\title{
Eosinophils in COPD: how many swallows make a summer?
}

\author{
To the Editor:
}

There is considerable controversy over the place of the blood eosinophil as a biomarker in chronic obstructive pulmonary disease (COPD). Recent literature suggests its use in assessing responsiveness to inhaled corticosteroids (ICS) $[1,2]$ and in predicting exacerbations $[3,4]$. Other studies either wholly or partially refute these associations [5-7]. We suggest that what underlies this confusion is the failure to understand the temporal variation in the biomarker, and the inherent imprecision in the collection of associated end-point data.

The fact that blood eosinophils are affected by numerous factors, including diurnal, seasonal and hormonal variations, has been known for four decades $[8,9]$. In COPD, fluctuations in disease and treatment further increase this variability [10]. Thus, the reliance on a single estimation of eosinophil count at baseline of a randomised control trial would be highly unlikely to reflect accurately the overall pattern of blood eosinophilia, and therefore the relationship with exacerbation risk or treatment response. Recently, a minority of patients were shown to have persistent eosinophilia, with the majority either nonor episodically eosinophilic [11]. As RABE et al. [12] point out, the main questions are how many estimations are needed, and where does one draw the line?

We have retrospectively collected "real-world" data on the prevalence and variability of blood eosinophilia in COPD patients, both with and without a co-existing diagnosis of asthma, as part of an on-going audit to assess compliance with our local guidelines. We manually examined primary care electronic records for patients on the COPD register of general practices in the Hull and East Riding area of the UK. The last five available eosinophil counts were collected. The most recent eosinophil count was termed E1, the penultimate E2, and so on, up to a maximum of five eosinophil counts (E5). A COPD exacerbation was defined as requiring prescription of short-term oral steroids for COPD within 12 months of data collection.

Any absolute eosinophil count (E1-E5) of $\geqslant 0.30 \times 10^{9}$ cells per L was selected as our cut-off points for eosinophilia, to mirror local guidelines [13]. However, we also assessed $\geqslant 0.34 \times 10^{9}$ [4] and $\geqslant 0.45 \times 10^{9}$ [3], as used in previous reports. The proportion of eosinophilia was plotted against E1-E5. Continuous variables were described as median (interquartile range). Quasi-Poisson regression [14] adjusted for age, gender, predicted forced expiratory volume in $1 \mathrm{~s}$ (FEV1), the Medical Research Council (MRC) dyspnoea scale, smoking status and asthma co-diagnosis was employed, and adjusted rate ratios and $95 \%$ confidence intervals are reported. Missing data was handled with 40 multiple imputation datasets [15], using predictive mean matching for continuous variables, logistic regression for dichotomous variables and ordered logit regression for the MRC scale. Results were pooled according to RUBIN'S rules [16, 17]. The $\mathrm{R}$ version 3.4.1 software was used for statistical analysis. A p-value $<0.05 / 5$ (Bonferroni correction) was considered statistically significant.

There were 611 (320 male) patients in our cohort, from four general practices. 253 patients had a co-diagnosis of asthma. The median age was 68 (60-76) years and predicted FEV1 was 62\% (46-75\%). Ex-/non-smokers represented 59.2\% (362 out of 611) of the cohort, whereas $40.6 \%$ (248 out of 611 ) were current smokers.

95\% (581 out of 611 ) of our cohort had at least one pre-existing full blood count (FBC) in their records, and 54.5\% (333 out of 611 ) had five available FBCs. At our guideline cut-off point of $0.30 \times 10^{9}$ cells per L, we had a 30.1\% (175 out of 581) prevalence of eosinophilia at E1. Repeated measures progressively

@ERSpublications

Repeated measures of eosinophil counts increased the proportion of eosinophilic patients http://ow.ly/ LhnV30hlR5j

Cite this article as: Hamad GA, Cheung W, Crooks MG, et al. Eosinophils in COPD: how many swallows make a summer? Eur Respir J 2018; 51: 1702177 [https://doi.org/10.1183/13993003.02177-2017]. 
increased the overall proportion of eosinophilic patients to $46.1 \%$ (268 out of 581) for E5 (figure 1), with the largest increase of $7.75 \%$ (95\% CI 5.71-10.23\%) between E1 and E2. This trend can be also observed for other cut-off points in the literature.

When the relationship between blood eosinophils and exacerbations was examined at $0.30 \times 10^{9}$ cells per $\mathrm{L}$, $\mathrm{E} 1 \mathrm{had}$ an adjusted rate ratio of $1.15(0.79-1.68), \mathrm{p}=0.46$. At $\mathrm{E} 2$, the adjusted rate ratio had increased to 1.67 (1.16-2.39), $\mathrm{p}<0.01$. Further sampling to E5 had no significant additional effects on the rate ratio. Similar findings were observed at the $0.34 \times 10^{9}$ cells per $\mathrm{L}$ and $0.45 \times 10^{9}$ cells per L cut-off points, as well as when analysis was repeated using negative binomial regression.

The use of a single value to define blood eosinophilia is, by its very nature, arbitrary. Unsurprisingly, it is clear from our data that a greater proportion of the COPD population is defined as eosinophilic with lower cut-off points. Repeated sampling reveals an increase in the proportion of patients defined as eosinophilic in all cohorts. The rate of increase in the proportion of eosinophilic patients was dependent on the cut-off point. Thus, in figure 1 , the rate of increase at $0.45 \times 10^{9}$ cells per $\mathrm{L}$ is less than that seen at $0.30 \times 10^{9}$ cells per L. Further work will be needed to determine which measure provides the greatest sensitivity and specificity in reflecting the clinically important level of blood eosinophils as a biomarker. What is clear is that multiple measures are required.

Eosinophilia in E1 was not associated with an increased risk of exacerbation on multi-variable analysis. Eosinophilia in E2, E3, E4 and E5, on the other hand, had a statistically significant association with increased risk of exacerbation, even after Bonferroni correction. By taking repeated counts, the likelihood of underestimation of eosinophilia is ameliorated, but the risk of overestimation is increased. In terms of the risk of exacerbation, it appears from our analysis that two counts are required, with further estimations providing little, if any additional precision. Whether this also applies in the determination of therapeutic efficacy is unknown.

A further difficulty arises due to the different definitions of end-points. In different studies, exacerbations are variously defined and recorded, from adverse event reporting in clinical trials [2] to coded episodes within electronic records [3]. The latter are reliant on accurate data entry, coded correctly for subsequent electronic extraction. During our manual collection of data, there was a noticeable deficiency in coding community exacerbations and hospital admissions. This was particularly so in the non-numerical items that are not routinely coded. For example, we compared the accuracy of detecting hospital admissions by automated means in 50 patients. The manual search revealed eight episodes of admission in the past year; however, the automated search failed to detect a single episode.

The retrospective nature of our data collection is a limitation. It is not known whether eosinophil counts were recorded during stable disease or during exacerbation. However, we believe that our cohort is more representative of the real-world COPD population, as selection was based on a clinical diagnosis. Other

FIGURE 1 Proportion of eosinophilic patients above cut-off values with serial estimations $195 \%$ confidence intervals).

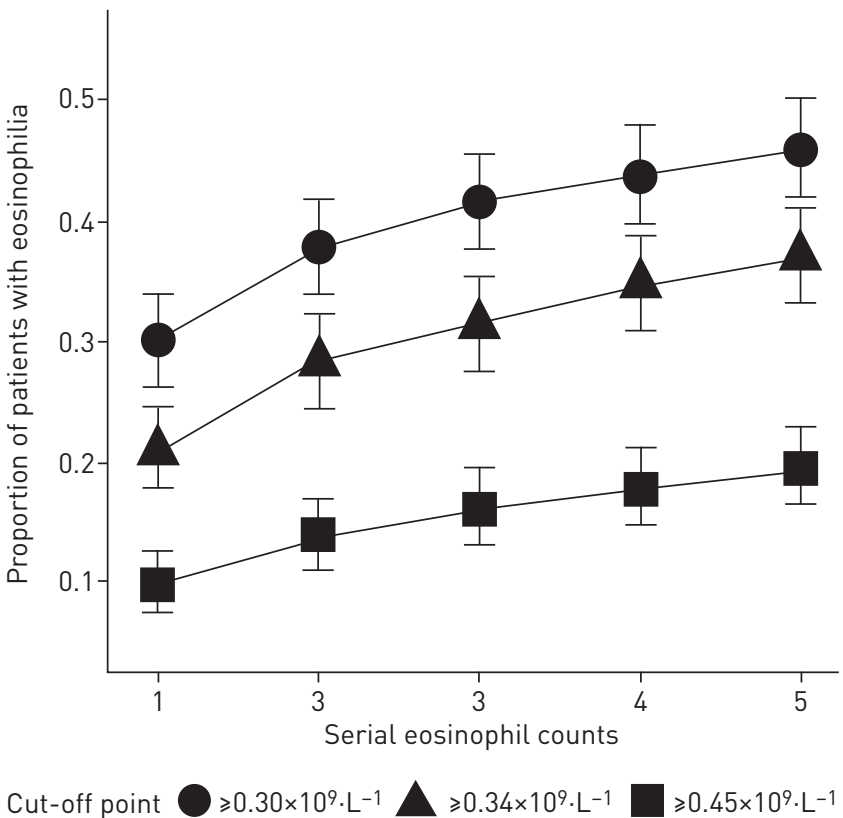


prospective and retrospective cohorts have strict spirometric criteria, which, whilst giving a more homogeneous cohort, might not reflect patients who are seen by clinicians in primary and secondary care.

In conclusion, we would recommend that a minimum of two or more eosinophil counts should be taken into account to determine the eosinophilic status of COPD patients. However, the eosinophil count should be considered in context, and not used as an absolute arbiter for decision making. Biomarkers, however good, are no replacements for clinical judgement.

Ghassan Ahmed Hamad, Wesley Cheung, Michael G. Crooks and Alyn H. Morice Academic Respiratory Medicine, Castle Hill Hospital, Cottingham, UK.

Correspondence: Alyn H. Morice, Head of Cardiovascular and Respiratory Studies, Hull York Medical School Castle Hill Hospital, Hull, HU16 5JQ, UK. E-mail: a.h.morice@hull.ac.uk

Received: Oct 232017 | Accepted after revision: Nov 062017

Support statement: This study was funded by AstraZeneca. Funding information for this article has been deposited with the Crossref Funder Registry.

Conflict of interest: Disclosures can be found alongside this article at erj.ersjournals.com

\section{References}

1 Hinds DR, DiSantostefano RL, Le HV, et al. Identification of responders to inhaled corticosteroids in a chronic obstructive pulmonary disease population using cluster analysis. BMJ Open 2016; 6: e010099.

2 Pavord ID, Lettis S, Locantore N, et al. Blood eosinophils and inhaled corticosteroid/long-acting beta-2 agonist efficacy in COPD. Thorax 2016; 71: 118-125.

3 Kerkhof M, Sonnappa S, Postma DS, et al. Blood eosinophil count and exacerbation risk in patients with COPD. Eur Respir J 2017; 50: 1700761.

4 Vedel-Krogh S, Nielsen SF, Lange P, et al. Blood Eosinophils and Exacerbations in Chronic Obstructive Pulmonary Disease. The Copenhagen General Population Study. Am J Respir Crit Care Med 2016; 193: 965-974.

5 Song JH, Lee CH, Kim JW, et al. Clinical implications of blood eosinophil count in patients with non-asthma-COPD overlap syndrome COPD. Int J Chron Obstruct Pulmon Dis 2017; 12: 2455-2464.

6 Turato G, Semenzato U, Bazzan E, et al. Blood eosinophilia does not reflect tissue eosinophils nor worsen clinical outcomes in COPD. Am J Respir Crit Care Med 2017; in press [https://doi.org/10.1164/rccm.201708-1684LE].

7 Zysman M, Deslee G, Caillaud D, et al. Relationship between blood eosinophils, clinical characteristics, and mortality in patients with COPD. Int J Chron Obstruct Pulmon Dis 2017; 12: 1819-1824.

8 Dahl R, Venge P, Olsson I. Blood eosinophil leucocytes and eosinophil cationic protein. Diurnal variation in normal subjects and patients with bronchial asthma. Scand J Respir Dis 1978; 59: 323-325.

9 Spector SL, Tan RA. Is a single blood eosinophil count a reliable marker for 'eosinophilic asthma'? J Asthma 2012; 49: 807-810.

10 Bafadhel M, Pavord ID, Russell REK. Eosinophils in COPD: just another biomarker? Lancet Respir Med 2017; 5: 747-759.

11 Casanova C, Celli BR, de-Torres JP, et al. Prevalence of persistent blood eosinophilia: relation to outcomes in patients with COPD. Eur Respir J 2017; 50: 1701162.

12 Rabe K, Beghe B, Fabbri L. Peripheral eosinophil count as biomarker for the management of COPD: not there yet. Eur Respir J 2017; 50: 1702165.

13 COPD Treatment Pathway: Hull \& East Riding Prescribing Committee; 2016 https://www.hey.nhs.uk/wp/ wp-content/uploads/2016/03/copdTreatmentPathway.pdf Date last updated: May 2016.

14 Ver Hoef JM, Boveng PL. Quasi-Poisson vs. negative binomial regression: how should we model overdispersed count data? Ecology 2007; 88: 2766-2772.

15 Graham JW, Olchowski AE, Gilreath TD. How many imputations are really needed? Some practical clarifications of multiple imputation theory. Prev Sci 2007; 8: 206-213.

16 Sterne JAC, White IR, Carlin JB, et al. Multiple imputation for missing data in epidemiological and clinical research: potential and pitfalls. BMJ 2009; 338: b2393.

17 van Buuren S, Groothuis-Oudshoorn K. MICE: Multivariate Imputation by Chained Equations in R. J Stat Softw 2011; 45: 67. 